\title{
Gastric Cancer: Environmental Risk Factors, Treatment and Prevention
}

\author{
Ahmed Al Saghier, Juma H Kabanja, Sehar Afreen and Mohamed Sagar* \\ Research Center, King Fahad Specialist Hospital Dammam (KFSH-D), Kingdom of Saudi Arabia
}

\begin{abstract}
Gastric Cancer is a heterogeneous, multifactorial, aggressive disease that has been and still remains one of the most common causes of cancer-related death and a major public health issue worldwide. Currently, gastric cancer shows decreasing trends in its incidence and mortality in some geographic areas; however the disease still shows poor prognosis and remains difficult to cure. The prognosis for patients with gastric cancer depends on the stage at which the gastric cancer is detected, and complete excision of the cancer is the only proven curative option However, recently the treatment of gastric cancer has been rapidly evolving with the emergence of new cytotoxic drugs and molecular targeted agents that show promising response rate and disease progression-free survival. Cancer prevention intervention such as screening to ensure early detection, population health education, anti-cancer knowledge popularization, identification and correction of unhealthy lifestyles has demonstrated to be effective; and improved treatment modalities can dramatically increase the poor prognosis for patients with gastric cancer.

Demographic, ecological, environmental, culture, and genetic variables all contribute to the heterogeneity of gastric cancer; however, environmental risk factors play an important role throughout all the stages of the disease progression, management and surveillance. In this review, we address the role of important environmental risk factors in the onset of gastric cancer, and highlight the current treatments modalities and prevention measures for gastric cancer
\end{abstract}

Keywords: Gastric cancer; Risk factors; Prevention; Treatment; Prognosis; Diet

Abbreviation: H. pylori: Helicobacter pylori; OR: Odds Ratio; EPIC: European Prospective Investigation into Cancer and Nutrition; BMI: Body Mass Index; RR: Relative Risk; CI: Confidence Interval; LN: Lymph Node; LADG: Laparoscopy-Assisted Distal Gastrectomy; EMR: Endoscopic Mucosal Resection; ESD: Endoscopic Submucosal Dissection; AJCC: American Joint Committee on Cancer; TNM: Tumor-Nodal-Metastasis: FLAGS: First-Line Advanced Gastric Cancer Study; HER2: Human Epidermal Growth Factor Receptor 2; ToGA: Trastuzumab for Gastric Cancer

\section{Introduction}

Gastric cancer has been and still remains one of the most common causes of cancer-related death and continues to be a major public health issue in spite of decreasing trends in its incidence and mortality [1-3]. Globally, gastric cancer accounts for 989,600 new cases and 738,000 deaths annually [3]. The case-fatality ratio of gastric cancer is higher than for common malignancies like colon, breast, and prostate cancers [3]. Relevant published studies show that the incidence of gastric cancer varies in different parts of the world, with higher incidence rates documented in Eastern Asia, Eastern Europe, and South America, while North America and Africa show the lowest recorded rates [3-5].

China alone accounting for $42 \%$ of all gastric cancer cases worldwide. This is at least in part because of its large population [5]. In 2010, it is estimated that 21,000 new cases of gastric cancer were diagnosed in the United States alone and approximately $50 \%$ of affected individuals died from the disease [6,7]. A number of Japanese men and women die from gastric cancer annually, representing approximately $15 \%$ of annual cancer-related deaths over the past four decades $[8,9]$. According to Globocan 2008, gastric cancer is the third most frequently diagnosed cancer and the second leading cause of cancer deaths in Japan, with an estimated 102,040 new cases and 50,156 cancer deaths in 2008 [8]. In Brazil, gastric cancer is the fourth most common cancer among men and sixth among women [10].

Gastric cancer may be subdivided into three distinct subtypes:
Proximal, diffuse, and distal gastric cancer- based on histopathologic and anatomic criteria. Each subtype is associated with unique epidemiology [11]. This uniqueness has been contributed by the multifactorial nature of gastric cancer which shows a complex interplay between genetics and both lifestyle and environmental factors [11]. A recent study shows that about $80-90 \%$ of gastric carcinomas develop in a sporadic setting, the remaining $10 \%$ to $20 \%$ show familial cluster, and approximately $1-3 \%$ have a clear inherited genetic susceptibility [12]. Although the etiology of gastric cancer is complex, the most important and well studied risk factors are Helicobacter pylori ( $H$. pylori) infections and host genetic factors, such as a positive family history for gastric cancer and/or a genetic pro-inflammatory profile. Environment and nutritional factors also seem to be important [4, 13-15]. Several environmental exposures have already been identified as risk factors for gastric cancer including diet, smoking, bacterial infections and a variety of occupational exposures [16].

Since significant regional differences in gastric cancer onset and prevalence have been observed, and this discrepancy may be attributed to the difference in environmental factors such as nutrition, smoking, occupational exposure, and bacterial infections. In this review, we address the role of important environmental risk factors in the onset of gastric cancer and highlight the current treatments modalities and prevention measures for gastric cancer.

*Corresponding author: Dr. Mohamed Sager, King Fahad Specialist Hospita Dammam Research Center, P.O.Box: 15215, Dammam 31444, Kingdom of Saud Arabia, Tel: 00966535807980; E-mail: mohamed.sager@kfsh.med.sa

Received May 26, 2013; Accepted June 15, 2013; Published June 25, 2013

Citation: Saghier AA, Kabanja JH, Afreen S, Sagar M (2013) Gastric Cancer: Environmental Risk Factors, Treatment and Prevention. J Carcinogene Mutagene S14: 008. doi:10.4172/2157-2518.S14-008

Copyright: (c) 2013 Saghier AA, et al. This is an open-access article distributed under the terms of the Creative Commons Attribution License, which permits unrestricted use, distribution, and reproduction in any medium, provided the original author and source are credited. 


\section{Gastric Carcinogenesis}

Our understanding of gastric carcinogenesis and prevention has been greatly shaped by seminal papers published during the last three decades. One of the first publications was Correa's multistep model of gastric carcinogenesis, which presents a well-accepted general hypothesis. In his hypothesis, gastric precancerous process for the intestinal type is defined as a multi-step and multi-factorial process, with the following sequential stages: chronic gastritis, atrophy, intestinal metaplasia, dysplasia and finally leading to gastric cancer [17]. Since publication of Correa's model, environmental risk factors have been shown to play an important role throughout all the stages of this process. Excessive salt intake and H. pylori infection have been shown to trigger the initial stages of gastritis and atrophy process. While the intermediate stages of the gastric precancerous process are generally characterized by the activity of ascorbic acid and nitrate, the final stages of the disease have been linked to the intake of beta carotene and salt [18].

\section{Helicobacter pylori}

Epidemiology studies: Since the 1983 discovery of $H$. pylori, its close association with peptic ulcers and gastric cancer has been documented in numerous studies. Although several prospective case-control studies have attempted to evaluate the link between $H$. pylori infection and the development of gastric cancer, studies are inconsistent in their findings [19-21]. Recently, association between gastric cancer and $H$. pylori has been evaluated by several authors using both meta-analysis and experimental models in Japanese and Chinese populations [8]. In Japan, both case-control and cohort studies have been conducted to estimate the degree of gastric cancer risk associated with $H$. pylori infection in the Japanese population. Four such prospective studies have shown a positive association, with RR ranging from 1.0 to 5.1 [22-25]. The largest prospective study of Sasazuki et al. [25] used the dataset of 511 cases and 511 control subjects), and showed that the adjusted odds ratio (OR) of gastric cancer associated with $H$. pylori infection was 5.1, which is quite similar to the estimate of 5.9 for non-cardia gastric cancer in a combined analysis of 12 casecontrol studies nested within prospective cohorts [26]. In other studies conducted on Chinese populations, the positive association of gastric cancer with $H$. pylori infection was also observed. In the publication by Lin et al., it was reported that a prospective, nested case-control study conducted in Linxian (one of the high-incidence regions in China) found that $H$. pylori seropositivity resulted in an approximately 2 -fold increased risk of gastric cancer. They also found that the same result was confirmed by a 2007 case-cohort study, in which $H$. pylori was associated with a 1.6-fold increased risk of both cardia and noncardia gastric adenocarcinomas [27]. Based on the substantial evidence from both case-control and cohort studies conducted, it is clear that $H$. pylori infection is causally linked to gastric cancer in the Japanese and Chinese population [8]. In 1994, the International Agency for Research on Cancer categorized H. pylori as a "Group 1 human carcinogen" based on a plethora of studies [28]. A prospective study by Uemura et al. 2001 [29] which included 1526 Japanese patients who had duodenal ulcers, gastric ulcers, gastric polyps and/ or non-ulcer dyspepsia reported a clear link between $H$. pylori and gastric carcinogenesis. In the Uemura study, it was observed that $2.9 \%$ of $H$. pylori infected patients subsequently developed gastric cancer while none of the uninfected patients developed tumors [29]. These evidences support the hypothesis that Helicobacter pylori is a human carcinogen and it is involved in the process of gastric carcinogenesis.
Experimental studies: Advances in moleculargenetics also continue to shape our understanding of the etiology of gastric cancer and the link with $H$. pylori. The identification of $H$. pylori as a risk factor for gastric carcinogenesis has stimulated extensive research on the mechanisms by which $H$. pylori induces carcinogenesis [30]. Recently, it has been observed in experimental studies that human gastric carcinogenesis is a multistep process whereby epithelial cells accumulate molecular alterations by genetic and epigenetic mechanisms involving oncogenes, tumor suppressor genes, DNA repair genes, cell cycle regulators, and signaling molecules. The genetic mechanism involves stable changes in the DNA sequence, whilst epigenetic alterations act via the methylation of CpG islands. The presence of $H$. pylori in the gastric mucosa can induce methylation of promoters containing $\mathrm{CpG}$ islands by activation of DNA methyltransferase. Furthermore, aberrant methylation of CpG islands is present along the multistep process of gastric carcinogenesis $[4,31,32]$. Another study by Kim et al. [33] demonstrated that H. pylori infection promotes gastric carcinogenesis by increasing endogenous DNA damage whilst decreasing repair activities, and by inducing mutations in the mitochondrial and nuclear DNA. Hence, it may be concluded that the aberrant DNA methylation and other molecular alterations observed in some genes induced by $H$. pylori infection are significant risk factors for gastric carcinogenesis.

\section{Lifestyle}

Before the discovery of H. pylori in 1983, epidemiologic studies had already suggested an important role of lifestyle in the etiology of gastric cancer. Since then, it has been noted that dietary factors are important environmental risk determinants for the development of many cancer types. The role of dietary factors in gastric cancer was studied in the last 40 years and received particular attention recently [34]. Here we have performed a systematic review to assess the relationship between environmental risk factors other than H. Pylori infection in the gastric carcinogenesis.

Diet: Research has clearly shown that differences in diet are an important factor in explaining variations in stomach cancer risk. Probably the best established associations that have been consistently confirmed in numerous studies throughout the world are those between cancer risk and diets containing an excessive intake of salt and a low intake of fresh fruits and vegetables [35].

High intake of salt food: Collective evidence from epidemiologic and experimental studies over the past several decades strongly suggests that high intake of salt/salty food is associated with an increased risk of gastric cancer. During early 1970's, it was shown that salted food has an explicit place in the sequence of gastric carcinogenesis. The acute effects of concentrated salt solutions lead to mucosal damage, and its repair is associated with inflammatory changes in the human stomach [17].

During the past few years, several experimental studies have been conducted with the aim to explore the mechanisms by which salt intake may increase gastric cancer risk; many mechanisms have been postulated although there has been no consistent conclusion [34] Some mechanisms that have been considered include:

(1)Destruction of the mucosal barrier: Intragastric high salt concentration destroys the mucosal barrier, through the increase of surface mucous cell mucin and the decrease of gland mucous cell mucin, leading to inflammation and damage such as diffuse erosion and degeneration. This in turn produces atrophic gastritis and 
decreases the acidity of the stomach. It creates a condition favoring $H$. pylori infection [36-38].

(2)Intestinal metaplasia: Intestinal metaplasia is also an important risk factor for gastric cancer. Mucosal damage in the stomach increases the rate of mitosis, leading to excessive cell replication and hyperplasia of the gastric pit epithelium with increased potential for mutations. Intestinal metaplasia characterized by the presence of caliciform cells in glands and in the foveolar gastric mucosa was detected near regenerative hyperplasia foci high $\mathrm{NaCl}$ diets animals. High salt intake will increase the concentration of $\mathrm{NaCl}$ in the stomach; then it may accelerate the procedure of intestinal metaplasia and increase the risk of gastric cancer in the future $[39,40]$.

(3)Hypergastrinemia: Gastrin itself may mediate epithelial cell growth in $\mathrm{H}$. pylori-colonized mucosa and induce hypergastrinemia. Chronic hypergastrinemia can synergize with Helicobacter infection and lead to eventual parietal cell loss and progression to gastric cancer [41-43].

Case-control and meta-analysis studies: Sheng Ge et al. in 2012 [34], carried out a systematic review to assess the relationship between habitual dietary salt intake and risk of gastric cancer in different geographic areas of the world. The comprehensive review included case-control studies and cohort studies published between January 1992 and January 2012. In the evaluation, eleven studies (7 case controls and 4 cohorts) were included in the meta-analysis (total population: $n$ $=2076498$; events: $n=12039$ ). The combined ratio showed a significant positive association between high salt intake and gastric cancer compared with low salt intake (OR $=2.05,95 \%$ Confidence Interval (CI) $(1.60,2.62) ; P<0.00001)$. In subgroup meta-analysis, the findings were slightly different when analyses were restricted to salty food intake $(\mathrm{OR}=2.41,95 \% \mathrm{CI}(2.08,2.78) ; P<0.00001)$ as well as in Asia $(\mathrm{OR}=$ 1.27 95\% CI $(1.22,1.32) ; P<0.00001)$.

Sheng et al. [34], noted a clear trend toward a direct association between salt intake and gastric cancer risk among 11 individual studies that were included in the meta-analysis and statistically significance was observed in 9 of the studies. Stratifying by geographic region, the pooled ORs of gastric cancer for the high versus low categories of salt intake were 1.15 (95\% CI, $(0.88,1.52))$. In studies conducted in Europe, there was no statistically significant heterogeneity among studies of salt intake in Europe $(P=0.19$ and $I 2=41 \%)$; and 1.27 (95\% CI, (1.22, 1.32)). In studies conducted in Asia with stratification according to geographic region, there was statistically significant heterogeneity among studies of salt intake in Asia $(P<0.00001$ and $I 2=95 \%)$ [34]. In addition, in an ecological study from China, Kneller et al. explored the association between the gastric cancer mortality rate and the results from a survey on diet, lifestyle and biochemical markers. The authors found a significant positive association between salted vegetables and egg consumption and the gastric cancer mortality rate [44].

Another recent publication also observed that the consumption of large amounts of salted fish, soy sauce, pickled vegetables, cured meat and other salt-preserved foods enhanced H. pylori colonization, and increased the risk of gastric cancer through direct damage to the gastric mucosa resulting in gastritis [42]. Salt is also known to induce hypergastrinemia and endogenous mutations, promoting epithelial cell proliferation which eventually leads to parietal cell loss and gastric cancer progression $[37,42]$. Therefore, from the positive association that has been observed between high salt intake in various geographic regions and gastric cancer, together with results of experimental studies, it can be strongly concluded that high salt intake fits into the process of gastric carcinogenesis.

Nitrate, nitrite and $\mathrm{N}$-nitroso compounds: Many experiments on animals have proven that $\mathrm{N}$-nitroso compounds are carcinogenic [45-48], but up to date there is no statistical significant data from many epidemiologic studies to support Nitrite or nitrosamine intake in relation to gastric cancer risk. However, our understanding of the association of nitrite and nitrosamines has changed due to overwhelming evidences on how these compounds can stimulate or participate in the process of formation of gastric cancer. It is well known that dietary nitrates are found either naturally in foods such as cabbage, cauliflower, carrot, celery, radish, beets, and spinach or added during preservation [4]. Also, small quantities of preformed $\mathrm{N}$-nitroso compounds and nitrosamines may be present in some foods including cured meats, dried milk, instant soups, and coffee dried on direct flame. In addition, the nitrate content of fertilizers, soil, and water also contribute to dietary nitrate. Nitrite, nitrate, and nitro sating agents can be synthesized endogenously by reactions mediated by bacteria and/or activated macrophages. Nitrosation of a number of naturally occurring guanidine's and L-arginine-containing polypeptides produces mutagenic compounds $[49,50]$. In one study, it is observed that dietary nitrate is converted to carcinogenic $\mathrm{N}$-nitroso compounds by gastric acid, thereby increasing gastric cancer risk [51]. Until recently neither cohort nor case-control studies have been conducted to examine the risk of gastric cancer in relation to nitrite or nitrosamine intake in large populations such as China and Japan where the prevalence of gastric cancer is high [8], but a number of case-control studies have found that high intake of preserved fish and preserved vegetables is significantly associated with increased risk of gastric cancer [52].

Vegetables and fruits: It has been suggested in many studies over the last few decades that vegetables and fruits, especially when consumed raw, lead to a decrease in gastric cancer incidence. Recently, the association between fruit and vegetable consumption and risk of gastric cancer has been explored in numerous studies, in both highand low-risk countries. Some case-control studies from Europe, Asia, and North America have consistently found intakes of both fruits and vegetables to be protective against gastric cancer, reducing the risk by approximately $40 \%$ by the consumption of fruits and $30 \%$ by consuming vegetables $[51,53,54]$. These findings were similar to an earlier study conducted in Japan based on 404 cases of gastric cancer revealed that vegetable and fruit intake, even in low amounts, lowers the risk for gastric cancer. Although no striking differences were seen in the association between cardia and non-cardia cancer, an inverse association was higher in differentiated rather than in undifferentiated types of gastric cancer [55]. In other studies conducted to establish the relationship between vegetable consumption and gastric cancer, it was observed that populations at high risk for stomach cancer have been shown to consume diets rich in starch and poor in protein quality, and are not inclined to eat fresh fruits and vegetables. Observations in these studies led to the conclusion that both high starch and low protein diets may favor acid-catalyzed nitrosation in the stomach and cause mechanical damage to the gastric mucosa [56-58]. Fruit consumption confers benefits due to the potential anticarcinogenic properties of fruits and it is believed to be related to the presence of antioxidant carotenoids or other phytochemicals [59].

Some inconsistencies in findings among various studies has been noted; meta-analysis conducted by Lunet et al. [60] found overall weaker associations in the reduction of gastric cancer risk, from $18 \%$ for high intake of fruits to $12 \%$ for high intake of vegetables as 
opposed to what the associations reported in earlier studies [60]. The inconsistencies in the results may be due to differences in the kinds of vegetables and fruits being consumed, the methods of consumption and the limitations of the dietary recall methodology. But, in 2007 the Expert Panel of the World Cancer Research Fund released a report which concluded that fruit and non starchy vegetables might protect against gastric cancer [61].

Micronutrients: In a latest hypothesis of carcinogenesis, Correa has suggested that, in the development sequence of gastric cancer from atrophic to metaplastic mucosa, $\mathrm{N}$-nitroso compounds are possible mutants responsible for the progress of carcinogenesis. That process may be inhibited by naturally occurring antioxidants [62]. Vitamin C, carotene, vitamin E, selenium, falconoid and lycopene are widely known antioxidant nutrients that can help in preventing gastric cancer [63].

Vitamin C (ascorbic acid) is a natural, water-soluble antioxidant that is abundant in fruits and vegetables and can regenerate vitamin $\mathrm{E}$ from its oxidized form [64]. The results from many early case-control studies worldwide consistently confirm a negative association between dietary intake of vitamin $\mathrm{C}$ and gastric cancer risk [65-67]. However, recently inconsistent results were observed in both experimental studies and observational epidemiologic and randomized trials. In prospective cohort studies reported by Chu Liu et al., 2008 [51]; serum vitamin $\mathrm{C}$ levels were inversely associated with mortality from gastric cancer, while in another study, EPIC cohort, plasma vitamin C levels were associated with reduced risk for gastric cancer, and this inverse association was similar according to anatomic site (cardia vs. noncardia), histologic subtype (diffuse vs. intestinal), or H. pylori infection [68-70]. Furthermore, a study from China [71] and a prospective study from Switzerland [72] reported an opposite association between vitamin $\mathrm{C}$ levels and gastric cancer rates. However, a recent randomized trial in Japan among individuals with chronic gastritis reported that vitamin C slowed the progression of gastric mucosal atrophy, a pre-cancerous lesion of gastric cancer [73]. In that trial, daily treatment with $50 \mathrm{mg}$ or $500 \mathrm{mg}$ of vitamin $\mathrm{C}$ for five years significantly reduced the ratio of serum pepsinogen I/Il, a marker of gastric atrophy [73]. This finding supports the early observation by Webb et al. [74] on the relationship of vitamin $\mathrm{C}$ consumption on the rate of gastric cancer.

Data from experimental and animal studies indicate several potential mechanisms by which vitamin $\mathrm{C}$ may affect gastric carcinogenesis, including the following: Vitamin $\mathrm{C}$ reduces gastric mucosal oxidative stress and DNA damage, and gastric inflammation by scavenging reactive oxygen species; it inhibits gastric nitrosation reaction for the formation of $\mathrm{N}$-nitroso compounds by reducing nitrous acid to nitric oxide and producing dehydro-ascorbic acid in the stomach; it enhances host immunologic functions; it has a direct effect on $H$. pylori growth and virulence; and it inhibits gastric cell proliferation and induces apoptosis $[51,64,75]$.

Carotenoids: Carotenoids are lipid-soluble compounds that are rich in fruits and vegetables and responsible for the color of many fruits and vegetables. u-carotene, 3-carotene, lycopene, lutein/ zeaxanthin, and -cryptoxanthin are the most abundant carotenoids from the diet and in the circulation of humans. Several carotenoids (such as u-carotene, $\mathrm{n}$-carotene, and 3-cryptoxanthin) present in fruits and vegetables can be partially metabolized to retinol [76,77]. $ß$-carotene has been linked to the late stage of gastric carcinogenesis as a potential free radical scavenger, having an effect opposite to that caused by dietary salt [18]. Most case-control and cohort studies of the role of carotenoids in gastric carcinogenesis have found an inverse association between carotenoids in the diet and gastric cancer rates. A large cohort study by Chyou et al. reported lower dietary intake of $B$ and other carotenoids among patients who developed stomach cancer than among cancer-free subjects [78]. In an Interventional trial in Linxian, China, Taylor et al. found that cancer mortality rates over the entire 5.25-year period of observation was significantly reduced among people receiving $B$-carotene, vitamin $\mathrm{E}$ and selenium [34].

Green and black tea: Recently, a possible anticarcinogenic effect of green tea has been a topic in cancer epidemiology. Polyphenol extracts of green tea and related compounds are known to inhibit carcinogenesis in animal models and human cell lines. Black tea polyphenols are oxidated and polymerized in the process of fermentation and it remains uncertain whether they sustain their anticarcinogenic effects. A comparative case-referent study by Inoue et al. using hospital-based research program data from 1990 to 1995 in Nagoya, Japan, found that high intake of green tea ( 7 cups or more per day) conferred an OR for stomach cancer of 0.69 (95\% CI 0.48-1.00) [79]. Another prospective cohort study by Goldbohn et al. failed to confirm this association [80]. A similar lack of association between green tea and the risk of gastric cancer was concluded from two prospective Japanese studies, therefore potentially excluding polyphenols from the list of beneficial environmental factors [67]. Recently Sasazuki et al., investigated the relationship between green tea consumption and subsequent risk of gastric cancer at different anatomical subsites in a population-based prospective study observed a significant reduced risk of distal gastric cancer in women [73].

Capsaicin: A hospital based case control study from Mexico [81] reported that high consumption of jalapeno peppers (90-250 mg of capsaicin per day, approximately 9-25 jalapeno peppers per day) conferred an increased the risk of gastric cancer $(\mathrm{OR}=1.71 ; 95 \% \mathrm{CI}=$ 0.76-3.88) as compared to low-level consumers (0-29.9 $\mathrm{mg}$ of capsaicin per day, approximately 0 to less than 3 jalapeno peppers per day; $p$ for trend $=0.026$ ). This effect was independent of $H$. pylori status and other potential gastric cancer determinants and was higher among diffuse gastric cancer cases $(\mathrm{OR}=3.64 ; 95 \% \mathrm{CI}=1.09-12.2$; $\mathrm{p}$ for trend $=0.002)$ compared to intestinal gastric cancer cases $(\mathrm{OR}=1.36 ; 95 \%$ $\mathrm{CI}=0.31-5.89 ; \mathrm{p}$ for trend $=0.493)$. Since no significant interaction was found between capsaicin intake and $H$. pylori on gastric cancer risk, the study concluded that chili pepper consumption might be an independent determinant of gastric cancer in Mexico [81].

\section{Alcohol consumption and tobacco smoking}

Alcohol, a gastric irritant, is an important risk factor for gastric cancer [4]. For years, alcohol consumption and tobacco smoking have been noted to elevate the risk for the development of gastric cancer. This was explored in a case-control study from Poland; Jedrychowski et al. investigated the effects of tobacco smoking and vodka consumption on gastric cancer risk. They reported a significant association between smoking cigarettes without filters and the risk of intestinal cancer at the cardia $(\mathrm{RR}=2.27,95 \%$ CI $0.97-5.28)$ [82]. The study also revealed that the RR for gastric cancer increased with rising frequency and amount of vodka consumed. Those who drank vodka at least once a week had three times higher risk for gastric cancer than non-drinkers [82]. Manoharan et al. [83] also demonstrated a positive correlation between alcohol consumption and cigarette smoking with the blood lipid profile in gastric cancer patients. Data from another early metaanalysis of 14 case-control studies and two cohort studies reported that alcohol consumption was associated with a modest increase in risk for gastric cancer; the RR for an increase of $25 \mathrm{~g} /$ day of alcohol was 1.07 (95\%CI 1.04- 1.10) [84]. Since data from both experimental 
and epidemiologic studies provide little support for alcohol as a causal effect in the development of gastric cancer, the relationship between alcohol consumption and gastric cancer risk remains controversial.

The association between cigarette smoking and gastric cancer has been investigated in a number of epidemiologic studies, including both case-control and cohort studies, but the results are inconsistent [85]. However, recently new studies have confirmed the direct correlation between consumption of alcohol and tobacco and the risk of gastric cancer. The European Prospective Investigation into Cancer and Nutrition (EPIC) project found a significant association between the intensity and duration of cigarette smoking and gastric cancer risk [86]. Smoking habit also has been linked to the incidence of gastric cancer, in a study by González et al. [87], tobacco smoke has been reported to induce the development of precursor gastric lesions such as gastritis, ulceration, and intestinal metaplasia. As a result, smokers tend to have a higher incidence of $H$. pylori infection and gastroduodenal inflammation than non-smokers [87].

In Japan approximately $28.4 \%$ of gastric cancers are related to cigarette smoking, according to data from the Hisayama Study, a population-based prospective study of the combined influence of cigarette smoking and $H$. pylori infection [6]. This study found that cigarette smoking is significantly associated with increased risk of gastric cancer independent of H. pylori infection [88]. Data from the Hisayama study was similar to a systematic review and metaanalysis conducted by the Research Group for the Development and Evaluation of Cancer Prevention Strategies in Japan in 2006, the summary RR for current smokers were estimated to be 1.8 (95\% CI: 1.5-2.1) in men and 1.2 (1.1-1.4) in women [89]. Based on these results, the research group concluded that there is convincing evidence that tobacco smoking moderately increases the risk of gastric cancer in the Japanese population [89]. In China, a recent prospective study of men in Shanghai showed that among nondrinkers, smokers have an $80 \%$ greater risk of gastric cancer, suggesting that cigarette smoking and alcohol consumption exert independent effects on gastric cancer risk [90]. Although cigarette smoking is associated with an increased risk of gastric cancer, it remains unclear whether the observed positive association is homogeneous in terms of histologic type or anatomic location. Such information was not disclosed in most of the previous studies [8].

Body Mass Index (BMI): Increasing body weight may contribute to the increased trend of gastric cardia cancer, especially among men, but not for gastric non-cardia cancer [91,92]. Studies conducted in different populations on the BMI and the risk of cardiac cancer reveled positive association. In a study from China, Ji et al. [93] examined BMI and risk of stomach cancer by sub-sites in 1124 newly diagnosed cases and 1451 randomly selected controls for the time period between 1988 and 1989. ORs for gastric cancer at the cardia among men at the second, third and fourth quartiles of usual BMI were 1.4, 1.5 and 3.0, respectively. Similar findings were observed for women with excess weight. Study results did not show any association between BMI and distal gastric cancer in men (the risk for this gastric cancer sub-site was slightly elevated in women) [93].

Recently, a systematic review of four published US and European studies that evaluated the association between BMI and risk of gastric cardia adenocarcinoma reported that being overweight (BMI $\geq 25$ to $\left.<30 \mathrm{~kg} / \mathrm{M}^{2}\right)$ or obese $\left(\mathrm{BMI} \geq 30 \mathrm{~kg} / \mathrm{m}^{2}\right)$ was significantly associated with a 1.5-fold increase in risk of gastric cardia adenocarcinoma. [94]. Similar results were observed in the Netherlands Cohort Study [95]. The RRs of gastric cardia adenocarcinoma were 1.32 (95\% Cl 0.94-1.85) for overweight and 2.73 (95\% $\mathrm{Cl} 1.56-4.79)$ for obese men and women, compared to individuals with normal weight (BMI $\geq 20$ to $<25 \mathrm{~kg} / \mathrm{m}^{2}$ ) [95].

\section{Ionizing radiation}

The best evidence about the effect of radiation comes from Japan. Among the 79,972 survivors of the A-bomb dropped on Nagasaki and Hiroshima, 8613 first primary solid cancers were diagnosed between 1958 and 1987 [96]. More than 2600 of these were gastric cancers, which showed a linear dose effect correlation with the radiation dose. The excess risk value was $0.32(95 \% \mathrm{CI}=0.16$ to 0.50$)$. However, the effect might have been underestimated because the rate of gastric cancer is, in general, relatively high in the Japanese population.

\section{Occupational exposures and gastric cancer}

The role of occupational exposures as a risk factor for gastric cancer has not been well investigated. Study results are conflicting and make it difficult to draw definite conclusions. In a population-based case-control study from Montreal, Canada, Parent et al. [97] found an elevated risk of gastric cancer among forestry workers, motortransport workers, excavators and pavers, electric and electronic workers and food industry employees [97]. The substances that might have been connected with gastric cancer were crystalline silica, leaded gasoline, grain dust, hydraulic fluids, lead dust, zinc dust and glycol ethers. Another multicenter case-control study from Italy by Cocco et al. [98] examined the association of occupational exposure with gastric cancer involving interviews with 640 histologically confirmed male gastric cancer cases and 959 controls. A significantly increased risk was only observed among sailors, seamen and allied groups (OR 2.9 and OR 3.1). Non significant increases after 20 years of employment were observed among forestry workers, miners, janitors and cleaners. The findings in this study suggested that occupational exposure to a variety of compounds is not a strong risk factor for gastric cancer, but an association may exist [99].

In most recent comprehensive reviews, it was concluded that there is considerable evidence that occupations in coal and tin mining, metal processing, particularly steel and iron, and rubber manufacturing industries lead to an increased risk of gastric cancer [98]. Similar findings about the relationship between occupational exposure to dusty environments and stomach cancer including miners and quarrymen, construction and metal processing workers come from a recent study in Sweden [100]. Also, a positive correlation has been recognized between increased stomach cancer risk and a number of occupations including mining, farming, refining, and fishing as well as workers in processing rubber, timber, and asbestos [101,102]. Moreover, occupational exposure to dust and high temperature environments such as cooking, wood processing plants, food and related products machinery, was associated with a significant increased risk of gastric cancer of the diffuse subtype [103].

\section{Treatment}

Over the past two decades, efforts have been made to improve surgical techniques, adjuvant chemotherapy, preoperative chemotherapy and radiation [104]. However, gastric cancer remains difficult to cure, with very poor prognosis and the 5-year survival rate is only around 20 per cent due to systemic recurrence after curative surgical resection. Prognosis depends on the stage at which it is detected, and complete surgical resection remains the only curative modality for early stage gastric cancer [1]. Recently, the treatment of gastric cancer has been rapidly evolving with the emerging of new cytotoxic drugs and targeted 
biologic agents [104]. Multidisciplinary management of gastric cancer, where both surgical resection and the molecular targeting agents are incorporated into the treatment modality shows promising response rates and progression-free survival [104].

\section{Treatment for early gastric cancer}

Although surgery, including gastrectomy in combination with systemic lymph node (LN) dissection, is the current treatment of choice for gastric cancer [104,105]; Laparoscopy-Assisted Distal Gastrectomy (LADG) is widely accepted surgery for early gastric cancer in recent years. As a result, LADG has become prevalent in Japan as a surgery which is minimally invasive for the patients and provides them with a good quality of life afterwards [106]. The acceptability and safety of LADG for early gastric cancer has been shown, and it is considered a first line additional therapy after endoscopic resection in Japan [107110]. Moreover, with the improved detection rate of early gastric cancer in Japan, more minimally invasive treatments have been investigated, and the use of Endoscopic Mucosal Resection (EMR) has become widespread. This technique has the support of many endoscopists, including those in Western countries [1,111]. Other new modalities of endoscopic treatment include Endoscopic Submucosal Dissection (ESD), which also has become commonly performed in facilities across Japan, helping to dramatically increase the number of early gastric cancer cases treated endoscopically [112]. This corresponds with excellent postoperative results for early detected gastric cancer, with a 5 -year survival rate of over $90 \%$ in both Western countries and Japan [1].

Multi-modality for early cancer: Early gastric cancer is treated with surgery, usually followed by chemotherapy or combined chemoand radiotherapy. In some cases where surgical resectability is doubtful in initial presentation; neo-adjuvant chemotherapy is preferred. The survival benefit from combined modality therapy was proven by several trials, for example the Magic trial randomized patients to perioperative chemotherapy versus surgery alone and showed improvement of survival from $23 \%$ to $36 \%$ [113]. The aim of therapy is disease control and symptom management, which is achieved by chemotherapy in patients who have good performance status.

Preoperative therapy and postoperative therapy are also increasing as a modality for improving the prognosis of gastric cancer. However, preoperative therapy has certain potential advantages over postoperative therapy. According to Yixing et al. [104], preoperative therapy may downstage the tumor and potentially increase the rate of resectability while it may sterilize the operative field and thereby reduce the risk of tumor seeding. Furthermore, early administration of systemic chemotherapy in the preoperative setting may eliminate micrometastasis, and allows better radiation field design [105]. Clinically, preoperative chemoradiation is better tolerated [104]. However, studies conducted to assess the efficacy of preoperative chemoradiation like that of Ajani et al., and Okawara et al. [114-116], have a relatively small number of patients.

\section{Treatment for gastric cancer in advanced stages}

Surgical resection with regional lymphadenectomy is the treatment of choice for patients with stage II gastric cancer. According to the new American Joint Committee on Cancer (AJCC) $7^{\text {th }}$ edition, TumorNodal-Metastasis (TNM) staging classification Stage II gastric cancer is an intermediate stage between stage I and stage III. Stage II gastric cancer is defined as a tumor that invades into or through the muscular wall of the stomach, but not into nearby local structures, or has regional
LN involvement with any extent of primary cancer, but no invasion of local structures [117]. However, preoperative and intraoperative staging to confirm the stage II disease is difficult. Failure to distinguish stage II from stage I disease may lead to under- or over-treatment. Therefore, the identification of additional prognostic factors would help in detecting patients with poorer prognosis with stage II gastric cancer. It might be of clinical significance to select candidates for treatment considerations, such as the extent of lymph node dissection and further adjuvant and neoadjuvant chemotherapy [117].

Unlike early stage gastric cancer where surgical resection is the only curative modality, treatment of advanced gastric cancer is difficult and the combination of surgical and adjuvant chemotherapy or radiation is required for better outcomes [117]. Currently, both single-agent and combination chemotherapy have been used in advanced metastatic gastric cancer. Active agents have included 5-FU, cisplatin, mitomycin C, doxorubicin, epirubicin, and etoposide, with RRs which vary from 10 to $20 \%$ [118-121].

S-1 (TS-1, Tiho Pharmacetical) is an effective adjuvant treatment for East Asia patients who have undergone extended lymph-node dissection [122]. The toxicity profile was very favorable. Although S-1 may impact the clinical practice in the Asian population, the results of this agent in Western populations are rather disappointing as demonstrated in the First-Line Advanced Gastric Cancer Study (FLAGS) [123]. This may be due to biological differences between patient populations as to how the drug is metabolized [123].

Targeted therapy is marginally successful in gastric cancer, Trastuzumab, an anti-Human epidermal growth factor receptor 2 (HER2) antibody, is approved and effective for treatment of HER2positive gastric adenocarcinoma [124]. The benefit of chemotherapy has been evaluated in the Trastuzumab for Gastric Cancer (ToGA) trial, Trastuzumab improved 5 -year overall survival by 3 months and subgroup analysis showed increased benefits in patients with high levels of HER2 protein expression. In an another meta-analysis from randomized phase II and III trials, Wagner et al. [124] show that chemotherapy is better than best supportive care, combination chemotherapy with doublet is superior than single agent, and the best survival is achieved with three agents at the cost of more toxicities. However, Roth et al. [125] suggested that, Palliative chemotherapy in patients with metastatic gastric cancer should be individualized.

\section{Prevention}

Prevention and improved treatment can dramatically improve the poor prognosis of gastric cancer. A key in designing prevention strategies is the discrimination of the general population and individual persons into high, intermediate, and low-risk categories for developing gastric cancer [126].

Currently, general and population specific approaches have been introduced as strategies to prevent and control the prevalence of gastric cancer. In 2004, Correa et al., [127] have suggested a plausible program for gastric cancer prevention that involves screening and treatment of $H$. pylori infection, endoscopic and histologic surveillance of precancerous lesions, improved sanitation and hygiene, restriction of dietary salt, and intake of a balanced diet containing fresh fruits and vegetables rich in antioxidants.

In Asia, The Asian Pacific Gastric Cancer Consensus [128] has recommended population-based screening and treatment of $H$. pylori infection in regions with an annual gastric cancer incidence above 20/100,000 to reverse $H$. pylori-induced biochemical, genetic, and 
epigenetic changes. In addition, the American and European guidelines recommended eradication of $H$. pylori in all patients with atrophy and/ or intestinal metaplasia and in all first-degree relatives of gastric cancer patients in addition to endoscopic and histological surveillance [4]

The strong causal link between $H$. pylori and gastric cancer presents a unique opportunity for considering antibiotic eradication treatment as a chemo-preventive strategy against a neoplastic disease [129]. Current evidence suggests that, in a subpopulation of the treated subjects, $H$. pylori eradication prevents the progression of preneoplastic lesions [13]. Studies have attempted to evaluate the effect of $H$. pylori eradication on the incidence of gastric cancer; however inconsistence results have been reported. Correa et al. assessed the effect of anti- $H$. pylori therapy on intestinal metaplasia, multifocal atrophy and dysplasia in a high gastric cancer risk region of Colombia [127]. In this prospective, randomized study relatively large number of patients were followed up for a long period; follow-up endoscopic assessment was carried out at 3, 6 and 12 years. Results of the 6-year follow-up evaluation showed that $H$. pylori eradication treatment produced a significant increase in the rates of regression for both preneoplastic lesions (intestinal metaplasia and atrophy) [127].

Currently, the possibility to perform screening for early detection of gastric cancer has resulted in decreasing in mortality in high risk areas. For example, in Japan, where the use of screening procedures is very frequent, gastric cancer incidences have halved since 1970 [130]. In Japan, following the introduction of a mass screening program that utilizes double-contrast barium radiography for the early detection of gastric cancer and alongside developments in endoscopic equipment and improved diagnostic capability, gastric cancer is now being detected more often in the asymptomatic stages [1]. Moreover, the excellent postoperative results for early gastric cancer, with a 5-year survival rate of over $90 \%$ in both Western countries and Japan, indicate just how important it is to detect the cancer at the earliest possible stage [1].

Since diet and dietary factors played an important role in the stages of gastric carcinogenesis, and so is risk factors for gastric cancer, modulation of dietary patterns and changes in cooking practices are believed to significantly reduce gastric cancer risk [127]. Dietary modification by reducing the intake of salt and salted food, as well as by increasing the intake of fruits and vitamin $\mathrm{C}$ is thus considered a practical strategy to prevent gastric cancer $[37,56,131,132]$.

In addition, both green and black tea consumption also has been reported to be associated with reduced risk of stomach cancer in epidemiological and experimental studies [129,133]. Vegetables and fruits also offer protection against gastric cancer. Several studies have demonstrated the protective effect of high intake of raw vegetables and fruits against the risk of gastric cancer. Best example is a reanalysis of the beneficial effects of fruit and vegetables in a continuation of the EPIC study involving 477312 subjects including 683 gastric adenocarcinoma patients with 11 years of follow-up found that intake of fresh fruits and citrus fruits protected against the risk of diffuse and cardia gastric cancer respectively [134].

Food products which offer antioxidant properties are also shown to provide protective power against the development of gastric cancer. In an EPIC study that recruited a total of 521457 subjects in 23 centers across 10 European countries found a positive association between high intake of dietary antioxidants and reduced risk of gastric cancer [135]. Result from this study support an early finding of Wang et al. [136], in his intervention trials, which confirmed that subjects at high risk of developing stomach cancer can be protected by supplementation with antioxidants.

Nutritional chemoprevention is the ideal strategy that has been proposed for prevention of gastric cancer by taking the advantage of the role of diet in the etiology of the disease. Chemoprevention approach involves the use of specific natural or synthetic chemical agents to reverse, suppress or prevent premalignancy from progressing to invasive cancer. Many dietary agents, medicinal plants and their constituent phytochemicals have received growing attention as potential chemopreventive agents over the past few years [137]. However, it has been suggested that, it is essential to test the chemopreventive efficacy of a putative agent in an animal model of gastric carcinogenesis before embarking on clinical trials.

\section{Conclusion}

The incidence of gastric cancer varies in different parts of the world with higher incidence rates documented in Eastern Asia, Eastern Europe, and South America, while North America and Africa show the lowest rates recorded.

In conclusion, based on the present evidence, it is likely that gastric cancer of the intestinal types is related to environmental exposure [138]. Gastric mucosal damage and atrophic gastritis can be caused by either $H$. pylori infection and/or by a diet lacking fresh fruits and vegetables and abundant in highly salted or poorly preserved foods. Subsequently, anti-oxidants and salt play an important role in the more advanced stages of gastric carcinogenesis. Regardless of the abundance of evidence pointing to the importance of environmental factors in the development of gastric cancer, these studies have the limitation of being retrospective and based largely on the dietary recall of the patients and controls [138]. In addition, many of these studies may not have considered sufficiently confounding factors that are typically hampering epidemiological studies particularly those dealing with environmental factors such as dietary patterns or occupational exposures using retrospective data.

In the future, well-designed prospective studies or intervention trials are needed to form a more accurate perception of the co-relation between the environmental factors and the development of gastric cancer.

\section{Acknowledgements}

We are grateful to the Research administration of the King Fahad Specialis Hospital-Dammam (KFSH-D) for providing resources for this manuscript. We also would like to thank the KFSH-D library staff for providing technical assistance in access to medical literature.

\section{References}

1. Yada T, Yokoi C, Uemura N (2013) The current state of diagnosis and treatment for early gastric cancer. Diagn Ther Endosc.

2. Ferlay J, Shin HR, Bray F, Forman D, Mathers C, et al. (2010) Estimates of worldwide burden of cancer in 2008: GLOBOCAN 2008. Int J Cancer 127: 2893-2917.

3. Jemal A, Bray F, Center MM, Ferlay J, Ward E, et al. (2011) Global cancer statistics. CA Cancer J Clin 61: 69-90.

4. Nagini S (2012) Carcinoma of the stomach: A review of epidemiology pathogenesis, molecular genetics and chemoprevention. World J Gastrointest Oncol 4: 156-169.

5. Parkin D, Whelan S, Ferlay W, Teppo L, Thomas D (2002) Cancer incidence in five continents. Volume VIII. IARC Sci Publ 155: 1-781.

6. Masciari S, Dewanwala A, Stoffel EM, Lauwers GY, Zheng H, et al. (2011) Gastric cancer in individuals with Li-Fraumeni syndrome. Genet Med 13: 651657. 
7. Seer Cancer Statistics Review 1975-2006

8. Lin Y, Ueda J, Kikuchi S, Totsuka Y, Wei WQ, et al. (2011) Comparative epidemiology of gastric cancer between Japan and China. World J Gastroenterol 17: 4421-4428.

9. Anonymous (2007) Vital Statistics of Japan 1968-2007 (in Japanese) Tokyo: Ministry of Health, Labour and Welfare, Japan.

10. Zilberstein B, Malheiros C, Lourenço LG, Kassab P, Jacob CE, et al. (2013) Brazilian consensus in gastric cancer: guidelines for gastric cancer in Brazil. Arq Bras Cir Dig 26: 2-6.

11. Shah MA, Khanin R, Tang L, Janjigian YY, Klimstra DS, et al. (2011) Molecular classification of gastric cancer: a new paradigm. Clin Cancer Res 17: 26932701.

12. Corso G, Roncalli F, Marrelli D, Carneiro F, Roviello F (2013) History, pathogenesis, and management of familial gastric cancer: original study of John XXIII's family. Biomed Res Int 2013: 385132

13. Fuccio L, Zagari RM, Minardi ME, Bazzoli F (2007) Systematic review: Helicobacter pylori eradication for the prevention of gastric cancer. Aliment Pharmacol Ther 25: 133-141.

14. González CA, Jakszyn P, Pera G, Agudo A, Bingham S, et al. (2006) Meat intake and risk of stomach and esophageal adenocarcinoma within the European Prospective Investigation Into Cancer and Nutrition (EPIC). J Nat Cancer Inst 98: 345-354.

15. González CA, Pera G, Agudo A, Bueno-de-Mesquita HB, Ceroti M, et al (2006) Fruit and vegetable intake and the risk of stomach and oesophagus adenocarcinoma in the European Prospective Investigation into Cancer and Nutrition (EPIC-EURGAST). Int J Cancer 118: 2559-2566.

16. Huang JQ, Sridhar S, Chen Y, Hunt RH (1998) Meta-analysis of the relationship between Helicobacter pylori seropositivity and gastric cancer. Gastroenterology 114: 1169-1179.

17. Correa P, Haenszel W, Cuello C, Tannenbaum S, Archer M (1975) A model for gastric cancer epidemiology. Lancet 2: 58-60.

18. Lauren $P(1965)$ the two histological main types of gastric carcinoma: diffuse and so-called intestinal-type carcinoma. An attempt at a histo-clinical classification. Acta Pathol Microbiol Scand 64: 31-49.

19. Forman D, Newell DG, Fullerton F, Yarnell JW, Stacey AR, et al. (1991) Association between infection with Helicobacter pylori and risk of gastric cancer: evidence from a prospective investigation. BMJ 302: 1302-1305.

20. Webb PM, Yu MC, Forman D, Henderson BE, Newell DG, et al. (1996) An apparent lack of association between Helicobacter pylori infection and risk of gastric cancer in China. Int J Cancer 67: 603-607.

21. Hansen S, Melby KK, Aase S, Jellum E, Vollset SE (1999) Helicobacter pylori infection and risk of cardia cancer and non-cardia gastric cancer. A nested case-control study. Scand J Gastroenterol 34: 353-360.

22. Watanabe Y, Kurata JH, Mizuno S, Mukai M, Inokuchi H, et al. (1997) Helicobacter pylori infection and gastric cancer. A nested case-control study in a rural area of Japan. Dig Dis Sci 42: 1383-1387.

23. Yamagata H, Kiyohara Y, Aoyagi K, Kato I, Iwamoto H, et al. (2000) Impact of Helicobacter pylori infection on gastric cancer incidence in a general Japanese population: the Hisayama study. Arch Intern Med 160: 1962-1968.

24. Yatsuya H, Toyoshima H, Tamakoshi A, Kikuchi S, Tamakoshi K, et al. (2004) Individual and joint impact of family history and Helicobacter pylori infection on the risk of stomach cancer: a nested case-control study. Br J Cancer 91: 929-934.

25. Sasazuki S, Inoue M, Iwasaki M, Otani T, Yamamoto S, et al. (2006) Effect of Helicobacter pylori infection combined with CagA and pepsinogen status on gastric cancer development among Japanese men and women: a nested casecontrol study. Cancer Epidemiol Biomarkers Prev 15: 1341-1347.

26. Helicobacter and Cancer Collaborative Group (2001) Gastric cancer and Helicobacter pylori: a combined analysis of 12 case control studies nested within prospective cohorts. Gut 49: 347-353

27. Kamangar F, Qiao YL, Blaser MJ, Sun XD, Katki H, et al. (2007) Helicobacter pylori and oesophageal and gastric cancers in a prospective study in $\mathrm{China} . \mathrm{Br}$ J Cancer 96: 172-176.

28. [No authors listed] (1994) Schistosomes, liver flukes and Helicobacter pylori.
IARC Working Group on the Evaluation of Carcinogenic Risks to Humans Lyon, 7-14 June 1994. IARC Monogr Eval Carcinog Risks Hum 61: 1-241.

29. Uemura N, Okamoto S, Yamamoto S, Matsumura N, Yamaguchi S, et al (2001) Helicobacter pylori infection and the development of gastric cancer. N Engl J Med 345: 784-789.

30. Houghton J, Wang TC (2005) Helicobacter pylori and gastric cancer: a new paradigm for inflammation-associated epithelial cancers. Gastroenterology 128: $1567-1578$

31. Tamura G (2004) Promoter methylation status of tumor suppressor and tumor-related genes in neoplastic and non-neoplastic gastric epithelia. Histo Histopathol 19: 221-228.

32. Kang GH, Shim YH, Jung HY, Kim WH, Ro JY, et al. (2001) CpG island methylation in premalignant stages of gastric carcinoma. Cancer Res 61: 2847 2851.

33. Kim SS, Ruiz VE, Carroll JD, Moss SF (2011) Helicobacter pylori in the pathogenesis of gastric cancer and gastric lymphoma. Cancer Lett 305: 228 238.

34. Ge S, Feng X, Shen L, Wei Z, Zhu Q, et al. (2012) Association between Habitual Dietary Salt Intake and Risk of Gastric Cancer: A Systematic Review of Observational Studies. Gastroenterol Res Pract 2012: 808120.

35. Fuchs CS, Mayer RJ (1995) Gastric carcinoma. N Engl J Med 333: 32-41.

36. Kato S, Tsukamoto T, Mizoshita T, Tanaka H, Kumagai T, et al. (2006) High salt diets dose-dependently promote gastric chemical carcinogenesis in Helicobacter pylori-infected Mongolian gerbils associated with a shift in mucin production from glandular to surface mucous cells. Int $\mathrm{J}$ Cancer 119: 1558 1566.

37. Tsugane S, Sasazuki S, Kobayashi M, Sasaki S (2004) Salt and salted food intake and subsequent risk of gastric cancer among middle-aged Japanese men and women. Br J Cancer 90: 128-134.

38. Campos F, Carrasquilla G, Koriyama C, Serra M, Carrascal E, et al. (2006) Risk factors of gastric cancer specific for tumor location and histology in Cali, Colombia. World J Gastroenterol 12: 5772-5779.

39. Kim J, Park S, Nam BH (2010) Gastric cancer and salt preference: a populationbased cohort study in Korea. Am J Clin Nutr 91: 1289-1293.

40. Peleteiro B, Lopes C, Figueiredo C, Lunet N (2011) Salt intake and gastric cancer risk according to Helicobacter pylori infection, smoking, tumour site and histological type. Br J Cancer 104: 198-207.

41. Peek RM Jr, Wirth HP, Moss SF, Yang M, Abdalla AM, et al. (2000) Helicobacter pylori alters gastric epithelial cell cycle events and gastrin secretion in Mongolian gerbils. Gastroenterology 118: 48-59.

42. Wang XQ, Terry PD, Yan H (2009) Review of salt consumption and stomach cancer risk: epidemiological and biological evidence. World J Gastroenterol 15 2204-2213.

43. Wang TC, Dangler CA, Chen D, Goldenring JR, Koh T, et al. (2000) Synergistic interaction between hypergastrinemia and Helicobacter infection in a mouse model of gastric cancer. Gastroenterology 118: 36-47.

44. Kneller RW, Guo WD, Hsing AW, Chen JS, Blot WJ, et al. (1992) Risk factors for stomach cancer in sixty-five Chinese counties. Cancer Epidemiol Biomarkers Prev 1: 113-118.

45. Inoue M, Tajima K, Kobayashi S, Suzuki T, Matsuura A, et al. (1996) Protective factor against progression from atrophic gastritis to gastric cancer--data from a cohort study in Japan. Int J Cancer 66: 309-314.

46. Mirvish SS (1983) The etiology of gastric cancer. Intragastric nitrosamide formation and other theories. J Natl Cancer Inst 71: 629-647.

47. Schoental R (1966) Carcinogenic activity of N-methyl-N-nitroso-N'nitroguanidine. Nature 209: 726-727.

48. Sugimura T, Fujimura S (1967) Tumour production in glandular stomach of rat by N-methyl-N'-nitro-N-nitrosoguanidine. Nature 216: 943-944.

49. Mitacek EJ, Brunnemann KD, Suttajit M, Caplan LS, Gagna CE, et al. (2008) Geographic distribution of liver and stomach cancers in Thailand in relation to estimated dietary intake of nitrate, nitrite, and nitrosodimethylamine. Nut Cancer 60: 196-203.

50. Suzuki H, lijima K, Scobie G, Fyfe V, McColl KE (2005) Nitrate and nitrosative chemistry within Barrett's oesophagus during acid reflux. Gut 54: 1527-1535. 
51. Liu C, Russell RM (2008) Nutrition and gastric cancer risk: an update. Nutr Rev 66: 237-249.

52. Jakszyn P, Gonzalez CA (2006) Nitrosamine and related food intake and gastric and oesophageal cancer risk: a systematic review of the epidemiological evidence. World J Gastroenterol 12: 4296-4303.

53. Lunet N, Valbuena C, Vieira AL, Lopes C, Lopes C, et al. (2007) Fruit and vegetable consumption and gastric cancer by location and histological type: case-control and meta-analysis. Eur J Cancer Prev 16: 312-327.

54. Anonymous (2003) IARC Handbooks on Cancer Prevention; Fruit and Vegetables 8: 387

55. Kobayashi M, Tsubono Y, Sasazuki S, Sasaki S, Tsugane S; JPHC Study Group (2002) Vegetables, fruit and risk of gastric cancer in Japan: a 10-yea follow-up of the JPHC Study Cohort I. Int J Cancer 102: 39-44.

56. Tsugane S, Sasazuki S (2007) Diet and the risk of gastric cancer: review of epidemiological evidence. Gastric Cancer 10: 75-83.

57. Krejs GJ (2010) Gastric cancer: epidemiology and risk factors. Dig Dis 28: 600 603.

58. Berretta M, Cappellani A, Lleshi A, Di Vita M, Lo Menzo E, et al. (2012) The role of diet in gastric cancer: still an open question. Front Biosci 17: 1640-1647.

59. Steinmetz KA, Potter JD (1991) Vegetables, fruit, and cancer. II. Mechanisms. Cancer Causes Control 2: 427-442.

60. Lunet N, Lacerda-Vieira A, Barros H (2005) Fruit and vegetables consumption and gastric cancer: a systematic review and meta-analysis of cohort studies. Nutr Cancer 53: 1-10

61. Epplein M, Shu XO, Xiang YB, Chow WH, Yang G, et al. (2010) Fruit and vegetable consumption and risk of distal gastric cancer in the Shanghai Women's and Men's Health studies. Am J Epidemiol 172: 397-406.

62. Correa P (1992) Human gastric carcinogenesis: a multistep and multifactoria process--First American Cancer Society Award Lecture on Cancer Epidemiology and Prevention. Cancer Res 52: 6735-6740.

63. Murphy PM, Blackshaw GR, Paris HJ, Edwards P, Barry JD, et al. (2004) Prospective evaluation of nutritional status related to body mass indices and outcomes after modified D2 gastrectomy for carcinoma. Clin Nutr 23: 477-483.

64. Zhang ZW, Farthing MJ (2005) The roles of vitamin C in Helicobacter pylor associated gastric carcinogenesis. Chin J Dig Dis 6: 53-58.

65. Correa P, Malcom G, Schmidt B, Fontham E, Ruiz B, et al. (1998) Review article: Antioxidant micronutrients and gastric cancer. Aliment Pharmacol Ther 12 Suppl 1: 73-82

66. Risch HA, Jain M, Choi NW, Fodor JG, Pfeiffer CJ, et al. (1985) Dietary factors and the incidence of cancer of the stomach. Am J Epidemiol 122: 947-959.

67. Buiatti E, Palli D, Bianchi S, Decarli A, Amadori D, et al. (1991) A case-contro study of gastric cancer and diet in Italy. III. Risk patterns by histologic type. Int J Cancer 48: 369-374.

68. Stähelin HB, Gey KF, Eichholzer M, Lüdin E, Bernasconi F, et al. (1991) Plasma antioxidant vitamins and subsequent cancer mortality in the 12-year follow-up of the prospective Basel Study. Am J Epidemiol 133: 766-775

69. Jenab M, Riboli E, Ferrari P, Sabate J, Slimani N, et al. (2006) Plasma and dietary vitamin $\mathrm{C}$ levels and risk of gastric cancer in the European Prospective Investigation into Cancer and Nutrition (EPIC-EURGAST). Carcinogenesis 27 2250-2257.

70. Jacobs EJ, Connell CJ, McCullough ML, Chao A, Jonas CR, et al. (2002) Vitamin $\mathrm{C}$, vitamin $\mathrm{E}$, and multivitamin supplement use and stomach cancer mortality in the Cancer Prevention Study II cohort. Cancer Epidemiol Biomarkers Prev 11: $35-41$.

71. You WC, Brown LM, Zhang L, Li JY, Jin ML, et al. (2006) Randomized doubleblind factorial trial of three treatments to reduce the prevalence of precancerous gastric lesions. J Natl Cancer Inst 98: 974-983.

72. Chen J, Geissler C, Parpia B, Li J, Campbell TC (1992) Antioxidant status and cancer mortality in China. Int J Epidemiol 21: 625-635.

73. Sasazuki S, Sasaki S, Tsubono Y, Okubo S, Hayashi M, et al. (2003) The effect of 5 -year vitamin $C$ supplementation on serum pepsinogen level and Helicobacter pylori infection. Cancer Sci 94: 378-382.

74. Webb PM, Bates CJ, Palli D, Forman D (1997) Gastric cancer, gastritis and plasma vitamin C: results from an international correlation and cross-sectional study. The Eurogast Study Group. Int J Cancer 73: 684-689.

75. Varis K, Taylor PR, Sipponen P, Samloff IM, Heinonen OP, et al. (1998) Gastric cancer and premalignant lesions in atrophic gastritis: a controlled tria on the effect of supplementation with alpha-tocopherol and beta-carotene. The Helsinki Gastritis Study Group. Scand J Gastroenterol 33: 294-300.

76. Wang $X(2004)$ Carotenoid oxidative/degradative products and their biologica activities. In: Krinsky NI, editor. Carotenoids in Health and Disease. 313-335.

77. Russell RM (1998) Physiological and clinical significance of carotenoids. Int $J$ Vitam Nutr Res 68: 349-353.

78. Inoue M, Tajima K, Hirose K, Hamajima N, Takezaki T, et al. (1998) Tea and coffee consumption and the risk of digestive tract cancers: data from a comparative case-referent study in Japan. Cancer Causes Control 9: 209-216.

79. Goldbohm RA, Hertog MG, Brants HA, van Poppel G, van den Brandt PA (1996) Consumption of black tea and cancer risk: a prospective cohort study. $J$ Natl Cancer Inst 88: 93-100.

80. Koizumi Y, Tsubono Y, Nakaya N, Nishino Y, Shibuya D, et al. (2003) No association between green tea and the risk of gastric cancer: pooled analysis of two prospective studies in Japan. Cancer Epidemiol Biomarkers Prev 12 $472-473$.

81. Dorant E, van den Brandt PA, Goldbohm RA, Sturmans F (1996) Consumption of onions and a reduced risk of stomach carcinoma. Gastroenterology 110 $12-20$.

82. Jedrychowski W, Boeing H, Wahrendorf J, Popiela T, Tobiasz-Adamczyk B, et al. (1993) Vodka consumption, tobacco smoking and risk of gastric cancer in Poland. Int J Epidemiol 22: 606-613.

83. Manoharan S, Kavitha K, Nagini S (1997) Role of life-style on plasma and erythrocyte membrane lipid profile in gastric cancer patients. Indian J Physio Pharmacol 41: 62-66.

84. Bagnardi V, Blangiardo M, La Vecchia C, Corrao G (2001) Alcohol consumption and the risk of cancer: a meta-analysis. Alcohol Res Health 25: 263-270.

85. Ladeiras-Lopes R, Pereira AK, Nogueira A, Pinheiro-Torres T, Pinto I, et al. (2008) Smoking and gastric cancer: systematic review and meta-analysis of cohort studies. Cancer Causes Control 19: 689-701.

86. Gonzalez CA, Pera G, Agudo A, Palli D, Krogh V, et al (2003) Smoking and the risk of gastric cancer in the European Prospective Investigation Into Cancer and Nutrition (EPIC). Int J Cancer 107: 629-634.

87. González CA, López-Carrillo L (2010) Helicobacter pylori, nutrition and smoking interactions: their impact in gastric carcinogenesis. Scand J Gastroenterol 45 : 6-14.

88. Shikata K, Doi Y, Yonemoto K, Arima H, Ninomiya T, et al. (2008) Populationbased prospective study of the combined influence of cigarette smoking and Helicobacter pylori infection on gastric cancer incidence: the Hisayama Study. Am J Epidemiol 168: 1409-1415.

89. Koizumi Y, Tsubono Y, Nakaya N, Kuriyama S, Shibuya D, et al. (2004) Cigarette smoking and the risk of gastric cancer: a pooled analysis of two prospective studies in Japan. Int J Cancer 112: 1049-1055.

90. Moy KA, Fan Y, Wang R, Gao YT, Yu MC, et al. (2010) Alcohol and tobacco use in relation to gastric cancer: a prospective study of men in Shanghai, China. Cancer Epidemiol Biomarkers Prev 19: 2287-2297.

91. Lindblad M, Rodríguez LA, Lagergren J (2005) Body mass, tobacco and alcoho and risk of esophageal, gastric cardia, and gastric non-cardia adenocarcinoma among men and women in a nested case-control study. Cancer Causes Control 16: 285-294

92. Ryan AM, Rowley SP, Fitzgerald AP, Ravi N, Reynolds JV (2006) Adenocarcinoma of the oesophagus and gastric cardia: male preponderance in association with obesity. Eur J Cancer 42: 1151-1158.

93. Ji BT, Chow WH, Yang G, McLaughlin JK, Gao RN, et al. (1997) Body mass index and the risk of cancers of the gastric cardia and distal stomach in Shanghai, China. Cancer Epidemiol Biomarkers Prev 6: 481-485

94. Kubo A, Corley DA (2006) Body mass index and adenocarcinomas of the esophagus or gastric cardia: a systematic review and meta-analysis. Cance Epidemiol Biomarkers Prev 15: 872-878.

95. Merry AH, Schouten LJ, Goldbohm RA, van den Brandt PA (2007) Body mass 
Citation: Saghier AA, Kabanja JH, Afreen S, Sagar M (2013) Gastric Cancer: Environmental Risk Factors, Treatment and Prevention. J Carcinogene Mutagene S14: 008. doi:10.4172/2157-2518.S14-008

index, height and risk of adenocarcinoma of the oesophagus and gastric cardia: a prospective cohort study. Gut 56: 1503-1511.

96. Chao A, Thun MJ, Henley SJ, Jacobs EJ, McCullough ML, et al. (2002) Cigarette smoking, use of other tobacco products and stomach cancer mortality in US adults: The Cancer Prevention Study II. Int J Cancer 101: 380-389.

97. Thompson DE, Mabuchi K, Ron E, Soda M, Tokunaga M, et al. (1994) Cancer incidence in atomic bomb survivors. Part II: Solid tumors, 1958-1987. Radiat Res 137: S17-67.

98. Cocco P, Palli D, Buiatti E, Cipriani F, DeCarli A, et al. (1994) Occupational exposures as risk factors for gastric cancer in Italy. Cancer Causes Control 5: 241-248

99. Parent ME, Siemiatycki J, Fritschi L (1998) Occupational exposures and gastric cancer. Epidemiology 9: 48-55.

100. Raj A, Mayberry JF, Podas T (2003) Occupation and gastric cancer. Postgrad Med J 79: 252-258.

101. Krstev S, Dosemeci M, Lissowska J, Chow WH, Zatonski W, et al. (2005) Occupation and risk of stomach cancer in Poland. Occup Environ Med 62: 318-324.

102. Straif K, Keil U, Taeger D, Holthenrich D, Sun Y, et al. (2000) Exposure to nitrosamines, carbon black, asbestos, and talc and mortality from stomach, lung, and laryngeal cancer in a cohort of rubber workers. Am J Epidemiol 152: 297-306.

103. Santibañez M, Alguacil J, de la Hera MG, Navarrete-Muñoz EM, Llorca J, et al. (2012) Occupational exposures and risk of stomach cancer by histological type. Occup Environ Med 69: 268-275.

104. Jiang Y, Ajani JA (2010) Multidisciplinary management of gastric cancer. Curr Opin Gastroenterol 26: 640-646.

105. Yokota T, Ishiyama S, Saito T, Teshima S, Shimotsuma M, et al. (2003) Treatment strategy of limited surgery in the treatment guidelines for gastric cancer in Japan. Lancet Oncol 4: 423-428.

106. Nakajima T (2002) Gastric cancer treatment guidelines in Japan. Gastric Cancer 5: 1-5.

107. Yoshida K, Yamaguchi K, Okumura N, Osada S, Takahashi T, et al. (2011) The roles of surgical oncologists in the new era: minimally invasive surgery for early gastric cancer and adjuvant surgery for metastatic gastric cancer. Pathobiology 78: 343-352.

108. Kim HH, Hyung WJ, Cho GS, Kim MC, Han SU, et al. (2010) Morbidity and mortality of laparoscopic gastrectomy versus open gastrectomy for gastric cancer: an interim report--a phase III multicenter, prospective, randomized Trial (KLASS Trial). Ann Surg 251: 417-420.

109. Ohtani H, Tamamori Y, Noguchi K, Azuma T, Fujimoto S, et al. (2010) A metaanalysis of randomized controlled trials that compared laparoscopy-assisted and open distal gastrectomy for early gastric cancer. J Gastrointest Surg 14: 958-964.

110. Jiang X, Hiki N, Yoshiba H, Nunobe S, Kumagai K, et al. (2011) Laparoscopyassisted gastrectomy in patients with previous endoscopic resection for early gastric cancer. Br J Surg 98: 385-390.

111. Tonouchi H, Mohri Y, Kobayashi M, Tanaka K, Ohi M, et al. (2007) Laparoscopy-assisted distal gastrectomy with laparoscopic sentinel lymph node biopsy after endoscopic mucosal resection for early gastric cancer. Surg Endosc 21: 1289-1293.

112. Soetikno R, Kaltenbach T, Yeh R, Gotoda T (2005) Endoscopic mucosal resection for early cancers of the upper gastrointestinal tract. J Clin Oncol 23: 4490-4498.

113. Cunningham D, Allum WH, Stenning SP, Thompson JN, Van de Velde CJ, et al. (2006) Perioperative chemotherapy versus surgery alone for resectable gastroesophageal cancer. N Engl J Med 355: 11-20

114. Ajani JA, Mansfield PF, Janjan N, Morris J, Pisters PW, et al. (2004) Multiinstitutional trial of preoperative chemoradiotherapy in patients with potentially resectable gastric carcinoma. J Clin Oncol 22: 2774-2780.

115. Ajani JA, Mansfield PF, Crane CH, Wu TT, Lunagomez S, et al. (2005) Paclitaxel-based chemoradiotherapy in localized gastric carcinoma: degree of pathologic response and not clinical parameters dictated patient outcome. J Clin Oncol 23: 1237-1244.
116. Ajani JA, Winter K, Okawara GS, Donohue JH, Pisters PW, et al. (2006) Phase II trial of preoperative chemoradiation in patients with localized gastric adenocarcinoma (RTOG 9904): quality of combined modality therapy and pathologic response. J Clin Oncol 24: 3953-3958.

117. Du CY, Chen JG, Zhou Y, Zhao GF, Fu H, et al. (2012) Impact of lymphatic and/or blood vessel invasion in stage II gastric cancer. World J Gastroentero 18: $3610-3616$

118. Barone C, Corsi DC, Pozzo C, Cassano A, Fontana T, et al (1998) Treatment of patients with advanced gastric carcinoma with a 5-fluorouracil-based or a cisplatin-based regimen: two parallel randomized phase II studies. Cancer 82 1460-1467.

119. Cullinan SA, Moertel CG, Fleming TR, Rubin JR, Krook JE, et al. (1985) A comparison of three chemotherapeutic regimens in the treatment of advanced pancreatic and gastric carcinoma. Fluorouracil vs fluorouracil and doxorubicin vs fluorouracil, doxorubicin, and mitomycin. JAMA 253: 2061-2067.

120. Cullinan SA, Moertel CG, Wieand HS, O'Connell MJ, Poon MA, et al. (1994) Controlled evaluation of three drug combination regimens versus fluorouracil alone for the therapy of advanced gastric cancer. North Central Cancer Treatment Group. J Clin Oncol 12: 412-416

121. Ohtsu A, Shimada Y, Shirao K, Boku N, Hyodo I, et al. (2003) Randomized phase III trial of fluorouracil alone versus fluorouracil plus cisplatin versus uracil and tegafur plus mitomycin in patients with unresectable, advanced gastric cancer: The Japan Clinical Oncology Group Study (JCOG9205). J Clin Oncol 21: 54-59.

122. Sakuramoto S, Sasako M, Yamaguchi T, Kinoshita T, Fujii M, et al. (2007) Adjuvant chemotherapy for gastric cancer with S-1, an oral fluoropyrimidine. N Engl J Med 357: 1810-1820.

123. Ajani JA, Rodriguez W, Bodoky G, Moiseyenko V, Lichinitser M, et al. (2010) Multicenter phase III comparison of cisplatin/S-1 with cisplatin/infusional fluorouracil in advanced gastric or gastroesophageal adenocarcinoma study: the FLAGS trial. J Clin Oncol 28: 1547-1553.

124. Wagner AD, Grothe W, Haerting J, Kleber G, Grothey A, et al. (2006) Chemotherapy in advanced gastric cancer: a systematic review and metaanalysis based on aggregate data. J Clin Oncol 24: 2903-2909.

125. Roth AD, Fazio N, Stupp R, Falk S, Bernhard J, et al. (2007) Docetaxel, cisplatin, and fluorouracil; docetaxel and cisplatin; and epirubicin, cisplatin and fluorouracil as systemic treatment for advanced gastric carcinoma: a randomized phase II trial of the Swiss Group for Clinical Cancer Research. J Clin Oncol 25: 3217-3223.

126. Roukos DH (2009) Genome-wide association studies and aggressive surgery toward individualized prevention, and improved local control and overall survival for gastric cancer. Ann Surg Oncol 16: 795-798.

127. Correa P, Piazuelo MB, Camargo MC (2004) The future of gastric cancer prevention. Gastric Cancer 7: 9-16.

128. Fock KM, Talley N, Moayyedi P, Hunt R, Azuma T, et al. (2008) Asia-Pacific consensus guidelines on gastric cancer prevention. J Gastroenterol Hepatol 23: 351-365.

129. Murugan RS, Mohan KV, Uchida K, Hara Y, Prathiba D, et al. (2007) Modulatory effects of black tea polyphenols on oxidant-antioxidant profile and expression of proliferation, apoptosis, and angiogenesis-associated proteins in the rat forestomach carcinogenesis model. J Gastroenterol 42: 352-361.

130. Patru C, Surlin V, Georgescu I, Patru E (2013) current issues in gastric cancer epidemiology. Rev Med Chir Soc Med Nat 117: 199-204.

131.Park B, Shin A, Park SK, Ko KP, Ma SH, et al. (2011) Ecological study for refrigerator use, salt, vegetable, and fruit intakes, and gastric cancer. Cancer Causes Control 22: 1497-1502.

132. D’Elia L, Rossi G, Ippolito R, Cappuccio FP, Strazzullo P (2012) Habitual salt intake and risk of gastric cancer: a meta-analysis of prospective studies. Clin Nutr 31: 489-498.

133.Yu GP, Hsieh CC, Wang LY, Yu SZ, Li XL, et al. (1995) Green-tea consumption and risk of stomach cancer: a population-based case-control study in Shanghai, China. Cancer Causes Control 6: 532-538.

134. Gonzalez CA, Lujan-Barroso L, Bueno-de-Mesquita HB, Jenab M, Duell EJ, et al. (2012) Fruit and vegetable intake and the risk of gastric adenocarcinoma: a reanalysis of the European Prospective Investigation into Cancer and Nutrition (EPIC-EURGAST) study after a longer follow-up. Int J Cancer 131: 2910-2919. 
Citation: Saghier AA, Kabanja JH, Afreen S, Sagar M (2013) Gastric Cancer: Environmental Risk Factors, Treatment and Prevention. J Carcinogene Mutagene S14: 008. doi:10.4172/2157-2518.S14-008

135. Serafini M, Jakszyn P, Luján-Barroso L, Agudo A, Bas Bueno-de-Mesquita $\mathrm{H}$, et al. (2012) Dietary total antioxidant capacity and gastric cancer risk in the European prospective investigation into cancer and nutrition study. Int J Cancer 131: E544-554.

136. Wang GQ, Dawsey SM, Li JY, Taylor PR, Li B, et al (1994) Effects of vitamin/ mineral supplementation on the prevalence of histological dysplasia and early cancer of the esophagus and stomach: results from the General Population Trial in Linxian, China. Cancer Epidemiol Biomarkers Prev 3: 161-166.

137. Priyadarsini RV, Nagini S (2012) Cancer chemoprevention by dietary phytochemicals: promises and pitfalls. Curr Pharm Biotechnol 13: 125-136.

138. Aragonés N, Pollán M, Gustavsson P (2002) Stomach cancer and occupation in Sweden: 1971-89. Occup Environ Med 59: 329-337.

This article was originally published in a special issue, Cancer Diagnosis,

Treatment and Therapy handled by Editor(s). Dr. Said Dermime, King

Fahad Specialist Hospital Dammam, Saudi Arabia 